\title{
Maximal expiratory flow volume values evaluation among female quartz grinders
}

\begin{abstract}
Background: A recent review in silica dust exposed workers focused on airway obstruction and the variables used were forced vital capacity (FVC), $\mathrm{FEV}_{1}$ and $\mathrm{FEV}_{1 \%}$. The maximal expiratory flow volume (MEFV) values i.e., peak expiratory flow (PEF), $\mathrm{FEF}_{75}, \mathrm{FEF}_{50}$ and $\mathrm{FEF}_{25}$ are not only useful to differentiate obstructive and restrictive type of functional abnormalities, but also the site of airway obstruction i.e., larger airways by $\mathrm{PEF}, \mathrm{FEF}_{75}$ or smaller airways by $\mathrm{FEF}_{50}, \mathrm{FEF}_{25}$. Hence, studies on MEFV values are needed. Aims: To identify the site of airway obstruction among female quartz grinders. Settings and Design: Quartz grinding industry workers in Chota Udepur (Gujarat) by cross sectional study. Materials and Methods: The MEFV values were measured among 106 female quartz grinders using SP-10 computerized spirometer and predicted and percentage of predicted values were derived.The average MEF values were compared according to age $(<24 ; 25-34 ; 35-44$ and $>45$ $y r s)$. The percentage predicted MEFV values were compared between normal and chest $\mathrm{X}$-ray abnormal (silicosis and silico-tuberculosis) workers and between normal and abnormal spirometry (restrictive (R), obstructive (O) and $\mathrm{R}+\mathrm{O}$ ) workers. Statistical Analysis: Summary statistics, ANOVA and $\chi^{2}$-test. Results: Significantly high reduction in MEFV values in $>45 \mathrm{yr}$. Workers; significant loss in silicosis and silicotuberculosis pronouncing higher in silicotuberculosis workers; significantly higher impairment $\mathrm{R}+\mathrm{O}$ type of functional abnormal than other type of abnormalities. These indicated that site of obstruction is both in larger and smaller airways. Conclusions: The MEFV values indicated that the site of obstruction is in both in smaller and larger airways.
\end{abstract}

Key words: Maximal expiratory flow volume, quartz grinding, silicosis, silicotuberculosis

\section{INTRODUCTION}

Flow volume curve analysis has contributed to our basic understanding of mechanical events that occur during ventilatory effort. ${ }^{[1]}$ The maximal expiratory flow volume (MEFV) curve have become an essential tool to assess various dynamic lung function parameters in humans and commonly used test for serial distribution of airway obstruction ${ }^{[2]}$ and in diagnosing chronic obstructive disease in surveys of air pollution etc. ${ }^{[3]}$ Tests of peak flow (PEF), MEFR and even $\mathrm{FEV}_{1}$ reflect the air flow resistance offered chiefly by central 'larger' airways, where as tests of MMEF maximal flow at 50 and 25 percent of VC reflect airflow characteristics of peripheral or smaller airways revealing superiority of MEFV values (PEF, $\mathrm{FEF}, \mathrm{FEF}_{50}, \mathrm{FEF}_{25}$ ) in identifying the site of obstruction. ${ }^{[4]}$

Two recently reviewed articles on lung function in silica dust exposed workers ${ }^{[5,6]}$ indicated both restrictive (R) and obstructive (O) type of abnormalities. These were based on the conventional spirometric variables i.e., FVC, FEV1 and $\mathrm{FEV}_{1 \%}$. Studies on analysis of MEFV values in silica dust exposed found evidence of small airways obstruction in Singapore quarry workers ${ }^{[7]}$ and in Indian quarry workers. ${ }^{[8]}$ The Indian study pointed out that the effects are probably due to smoking than dust exposure. The MEFV values were not evaluated in relation to age and chest $\mathrm{X}$-ray abnormalities. Hence, in this present report MEFV values are assessed among 106 female quartz grinders exposed to silica dust using average and percentage of product values, to find out the site of airway obstruction.

\section{MATERIALS AND METHODS}

A large number of workers are employed in quartz grinding and are exposed to high levels of silica dust. To assess the respiratory health, this study was conducted among 106 female quartz grinders at Chota
Nellore Mohan Rao, Ramnath Takiar, Yashwant K. Sharma National Institute of Occupational Health (ICMR), Ahmedabad 380016, India

For correspondence: Dr. N. Mohan Rao, Respiratory Physiology Department,

National Institute of Occupational Health (ICMR),

Ahmedabad - 380 016, India. E-mail:

dmmohanrao@rediffmail.com

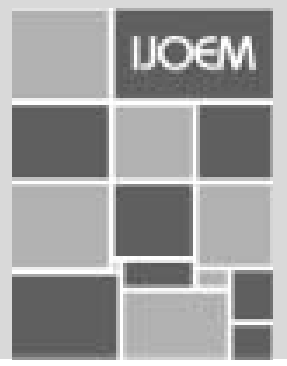


Udepur, Vadodara district, Gujarat State. Their anthopometric findings, personal and occupational history were noted. A thorough explanation and demonstration of MEFV curve measurement was made to all workers. The recordings were carried out in sitting posture using Spirovit-SP-10 computerized Spirometer, as per the American Thoracic Society (ATS) standards and results at BTPS level. The best curve was taken for analysis.

The average MEFV values i.e., $\mathrm{PEF} \mathrm{FEF}_{75^{\prime}} \mathrm{FEF}_{50}$ and $\mathrm{FEF}_{25}$ were obtained. The predicted values were computed using the regression equation ${ }^{[9,10]}$ and percentage of predicted values were determined. During this study chest X-ray was taken and X-ray diagnostic of all these workers were obtained. The percentage predicted values were observed according to age i.e., $<24 ; 25-34 ; 35-44$ and $>45$ yrs and compared. The values in relation to chest X-ray diagnosis i.e., normal, silicosis and silicotuberculosis were analyzed and compared with normal value. The prevalence conventional spirometric abnormalities were derived basing on the criteria. ${ }^{[1]}$ The MEFV values of abnormal spirometry were compared with normal spirometery.

The statistical tests used for evaluation are ANOVA, student t-test etc. The relevant results are discussed.

\section{RESULTS}

In Table 1 the anthropometric findings of 106 female quartz grinders and lung function test values are given. The MEFV value according to age is presented in Table 2 . The values of $\mathrm{PEF}, \mathrm{FEF}_{75}$ and $\mathrm{FEF}_{50}$ remained consistent from below 24 yrs up to 35-44 yrs age group with a markedly lowered value in

\begin{tabular}{lc}
$\begin{array}{l}\text { Table 1: Anthropometric findings of female quartz grinders } \\
\text { (values mean + S.D.) }\end{array}$ & $\mathbf{N}=\mathbf{1 0 6}$ \\
\hline Parameter & $29.7 \pm 9.6$ \\
\hline Age (yrs) & $149.7 \pm 5.7$ \\
Height (cm) & $39.4 \pm 6.2$ \\
Weight (kg) & \\
Maximal expiratory flow volume values $\left(\mathrm{IS}^{[1]}\right)$ & $4.08 \pm 1.44$ \\
PEF & $3.72 \pm 1.39$ \\
$\mathrm{FEF}_{75}$ & $2.76 \pm 1.12$ \\
$\mathrm{FEF}_{50}$ & $1.36 \pm 10.69$ \\
$\mathrm{FEF}_{25}$ & \\
\hline
\end{tabular}

Table 2: MEFV values (1/s) among female quartz grinders cccording to age group

\begin{tabular}{|c|c|c|c|c|}
\hline \multirow{2}{*}{$\begin{array}{l}\text { Parameter } \\
\left.\text { MEFV (IS }{ }^{[1]}\right)\end{array}$} & \multicolumn{4}{|c|}{ Age group (yrs) } \\
\hline & $\begin{array}{c}7-24 \\
N=31\end{array}$ & $\begin{array}{c}25-34 \\
N=38\end{array}$ & $\begin{array}{c}35-44 \\
N=28\end{array}$ & $\begin{array}{c}<45 \\
N=9\end{array}$ \\
\hline PEF & $4.11 \pm 1.55$ & $4.13 \pm 1.51$ & $4.16 \pm 1.26$ & $3.54 \pm 1.42$ \\
\hline $\mathrm{FEF}_{75}$ & $3.77 \pm 1.53$ & $3.78 \pm 1.48$ & $3.75 \pm 1.16$ & $3.26 \pm 1.25$ \\
\hline $\mathrm{FEF}_{50}$ & $2.83 \pm 1.97$ & $2.84 \pm 1.03$ & $2.81 \pm 0.97$ & $2.02 \pm 0.86^{\mathrm{N}}$ \\
\hline $\mathrm{FEF}_{25}$ & $1.41 \pm 0.76$ & $1.48 \pm 0.58$ & $1.31 \pm 0.73$ & $0.80 \pm 0.44^{*}$ \\
\hline
\end{tabular}

$\mathrm{N}=$ Number of workers; ${ }^{*}=$ Significant at $5 \%$ level, MEFV - Maximal expiratory flow volume above 45 yrs age group. Compared to $35-44$ yrs age group $\mathrm{FEF}_{50}$ and $\mathrm{FEF}_{25}$ was reduced significantly in 45 years above age group.

The percentage of predicted MEFV values according to chest $\mathrm{X}$-ray diagnosis is shown in Table 3. Normal X-ray was seen in 62 (58.5), silicosis 29 (27.4) and silicotuberculosis in 15 (14.2) quartz grinders. Normal chest X-ray workers have relatively well preserved their average MEFV values, where as silicosis and silicotuberculosis workers exhibited significant loss compared to normal X-ray workers. Even among silicosis workers, the mean values were above 80.0 percent predicted value. The loss is pronounced higher among silicotuberculosis than silicosis workers.

The percentage predicted value in relation to conventional spirometric abnormalities is presented in Table 4. Out of total 106, normal spirometry 75 (70.8\%), restrictive (R) type 18 (17.0\%), obstructive (0) type 9 (8.5\%) and combined $R+0$ type 4 (3.8\%) workers is observed. Compared to normal spirometry workers, the severity of reduction in MEFV values is higher among $\mathrm{R}+\mathrm{O}$ type of abnormal workers, followed by O-type and R-type. The R-type workers showed higher reduction in $\mathrm{FEF}_{50}$ and $\mathrm{FEF}_{25}$ than $\mathrm{O}$ type workers.

\section{DISCUSSION}

In healthy subjects, maximal flow rates at larger lung volume i.e., at the beginning of expiration $\left(\mathrm{PEF}, \mathrm{FEF}_{75}\right.$ ) are held to reflect mainly the flow characteristics of larger airways, while those at small lung volumes i.e. at the end of expiration $\left(\mathrm{FEF}_{50^{\prime}}\right.$

Table 3: MEFV values (\% predicted) according to chest X-ray abnormality

\begin{tabular}{lccc}
\hline $\begin{array}{l}\text { MEFV } \\
\text { (\% predicted) }\end{array}$ & \multicolumn{3}{c}{ Chest X-ray } \\
\cline { 2 - 4 } & $\begin{array}{c}\text { Normal } \\
\mathbf{N}=\mathbf{6 2}\end{array}$ & $\begin{array}{c}\text { Silicosis } \\
\mathbf{N}=\mathbf{2 9}\end{array}$ & $\begin{array}{c}\text { Silicotuberculosis } \\
\mathbf{N}=\mathbf{1 5}\end{array}$ \\
\hline $\mathrm{PEF}$ & $97.2 \pm 25.0$ & $84.0 \pm 34.7^{*}$ & $66.8 \pm 34.5$ \\
$\mathrm{FEF}_{75}$ & $119.9 \pm 32.3$ & $103.9 \pm 43.8^{*}$ & $79.9 \pm 40.7^{* *}$ \\
$\mathrm{FEF}_{50}$ & $106.5 \pm 29.8$ & $84.6 \pm 35.0^{* *}$ & $64.5 \pm 38.1^{* *}$ \\
$\mathrm{FEF}_{25}$ & $120.0 \pm 50.8$ & $79.0 \pm 41.9^{* *}$ & $60.9 \pm 35.7^{* *}$ \\
\hline
\end{tabular}

$\mathrm{N}=$ Number of workers, ${ }^{*}=$ Significant at $5 \%$ level compared to normal group,

${ }^{* *}=$ Significant at $1 \%$ level compared to normal group, MEFV - Maximal expiratory flow volume

Table 4: MEFV values (\% predicted) in relation to spirometric abnormalities

\begin{tabular}{|c|c|c|c|c|}
\hline \multirow{2}{*}{$\begin{array}{l}\text { MEFV (\% } \\
\text { predicted) }\end{array}$} & \multicolumn{4}{|c|}{ Spirometry } \\
\hline & $\begin{array}{l}\text { Normal } \\
N=75\end{array}$ & $\begin{array}{c}\text { Restrictive } \\
N=18\end{array}$ & $\begin{array}{c}\text { Obstructive } \\
\mathbf{N}=9\end{array}$ & $\begin{array}{c}\text { Combined } \mathbf{R}+0 \\
N=4\end{array}$ \\
\hline PEF & $97.2 \pm 25.0$ & $78.9 \pm 23.3^{*}$ & $62.5 \pm 26.1^{* *}$ & $34.2 \pm 20.0^{* *}$ \\
\hline $\mathrm{FEF}_{75}$ & $119.9 \pm 32.3$ & $92.1 \pm 35.4^{*}$ & $84.1 \pm 36.3^{* *}$ & $41.6 \pm 25.8^{* *}$ \\
\hline $\mathrm{FEF}_{50}^{15}$ & $106.5 \pm 29.8$ & $62.5 \pm 32.6^{* *}$ & $63.9 \pm 28.4^{* *}$ & $40.9 \pm 36.3^{* *}$ \\
\hline $\mathrm{FEF}_{25}^{50}$ & $120.1 \pm 50.8$ & $70.7 \pm 43.5^{* *}$ & $63.4 \pm 30.2^{* *}$ & $65.5 \pm 33.5^{*}$ \\
\hline
\end{tabular}

$\mathrm{N}=$ Number of workers, ${ }^{*}=$ Significant at $5 \%$ level compared to normal spirometry,

${ }^{* *}=$ Significant at $1 \%$ level compared to normal spirometry, MEFV - Maximal expiratory flow volume 
$\mathrm{FEF}_{25}$ ) reflect the characteristics of small airways. In these silica dust exposed workers of this present study, the dust deposition retention and tissue reactions occurred in all sites of airways i.e., both larger and smaller airways and in alveoli of the lung as evidenced by the reduced or loss in MEFV value that are associated with chest X-ray abnormality i.e., silicosis and silicotuberculosis. While the earlier reports in Singapore ${ }^{[7]}$ and in small $(\mathrm{N}=25)$ male quarry workers ${ }^{[8]}$ indicated the occurrence of smaller airway obstruction, but the present study in large number of female workers $(\mathrm{N}=106)$ the findings revealed obstruction in both larger and smaller airways. These female workers are from tribal area and are also exposed to biomass fuel air pollutants during cooking process at home, which may be an additional exposure that has bearing effect on respiratory system.

In MEFV curves, the flow and driving pressure at which flow limiting segments develop are determined by the mechanical properties of lung viz. (1) the static dimensions of airways (2) Lung elasticity reflected by static trans-pulmonary pressure (3) Dynamic narrowing of airways. The first two factors are determinants of airway resistance. ${ }^{[12,13]}$ These are affected by aging as well as dust exposure leading to much lowered values with a significant effect on $\mathrm{FEF}_{50}$ and $\mathrm{FEF}_{25}$ in higher age group (above 45 yrs).

Silicosis is a restrictive type of occupational lung disorder. An observation of MEFV values among silicosis workers [Table 3] and in R-type of abnormal workers [Table 4] revealed that values are more reduced in spirometric abnormal workers. Silicosis was seen in 29 (27.4\%) and among them R-type abnormality in 7 (24.1\%), 0-type 2 (6.9\%) and combined $\mathrm{R}+0$ type 2 (6.95) was seen indicating that nearly 18 workers are having normal spirometry. That is the reason for the differences in MEFV values. On the other hand among 15 silicotuberculosis workers, the prevalence of spirometric abnormalities are R-type 7(46.9\%), 0-type 3 (20.0\%) and combined $\mathrm{R}+\mathrm{O}$ type 1 (6.7\%) indicating higher prevalence than silicosis workers. This is in concurrence with the difference in MEFV values between silicosis and silicotuberculosis workers. It was reported ${ }^{[5]}$ that lung function with radiographic silicosis in category-1 was indistinguishable to those in category- 0 and in those in category-2 had small reduction in spirometric values. Reports indicated in both longitudinal ${ }^{[14]}$ and cross sectional ${ }^{[15]}$ epidemiological studies among silica dust exposed workers, those silicosis patients with a history Tuberculosis had a greater decline in FVC, $\mathrm{FEV}_{1}$ and this is also evidenced in this present study MEFV values. The MEFV values exhibited higher reduction in $\mathrm{R}+\mathrm{O}$ type abnormal workers followed by $\mathrm{O}$ type and R-type. In R-type abnormal workers there is impairment in $\mathrm{FEF}_{50}$ and $\mathrm{FEF}_{25}$ indicating impairment in smaller airways and smaller airways are the early indicator of airway obstruction in dust-exposed workers.

Epidemiological and pathological studies suggested that chronic levels of silica dust do not cause disabling silicosis, may cause the development of chronic bronchitis that can lead to airflow obstruction even in the absence of radiological silicosis. ${ }^{[6]}$ Smoking can potentate the silica dust exposure and smokers had significantly reduced MEFV values ${ }^{[16]}$ and studies among hard rock miners, the effect of silica dust on lung function is different in smokers compared to nonsmokers. ${ }^{[17]}$ Present study workers are all non-smokers and in normal chest X-ray workers, MEFV values are within the normal range. This rules out the effect of smoking on MEFV values in this present study.

Overall, this report showed that there is significant repercussions on MEFV values in silica dust exposed quartz grinders, pronounced higher among silicotuberculosis, combined $\mathrm{R}+0$ type of abnormal workers and in above 45 years age group.

\section{ACKNOWLEDGEMENT}

The authors acknowledge with thanks the help rendered by Baroda Medical College, TB Hospital, Chota Udepur during the course of this study. Thanks are also due to Mrs. Bharti Satose for providing her personal assistance. The authors acknowledge with thanks Dr. H. N. Saiyed, Director, National Institute of Occupational Health (ICMR) for granting permission to publish this article and to the staff of Baroda Medical College, TB Hospital, Chota Udepur during the course of this study.

\section{REFERENCES}

1. Hyalt RE, Black LF. The flow volume curve: A current perspective. Am Rev Respir Dis 1973;107:191-9.

2. Lambert RK, Beck KC. Airway area distribution from the forced expiration maneuver. J Appl Physiol 2004;97:570-8.

3. Meguro T, Ogata M. Analysis of maximal expiratory flow-volume curves-visual evaluation and quantitative evaluation. Nippon Eiseigaku Zashit 1991;46:625-34.

4. Murray JF. Chapter X Respiration p. 955. In text book of pathophysiology - The Biological principles of disease. Smith, Thier, editors. WB Saunders Company: Philadelphia; 1981.

5. Gamble JF, Hessel PA, Nicolich M. Relationship between silicosis and lung function. Scand J Work Environ Health 2004;30:5-20.

6. Hnizdo E, Vallyathan V. Chronic obstructive pulmonary disease due to occupational exposure to silica dust: A review of epidemiological and pathological evidence. Occup Environ Med 2003;60:237-43.

7. Chia KS, Ng TP, Jayaratnam J. Small airways function of silica exposed workers. Am J Indust. Med 1992;22:155-62.

8. Subhasini AS, Satehidanandan N. Maximal expiratory flow volume curve in quarry workers. Indian J Physiol Pharmacol 2002;46:78-84.

9. Udwadia FE, Sunavala JD, Shetye VM, Jain PK. The maximal expiratory flow volume curve in normal subjects in India. Chest 1986;89:852-6. 
10. Vijayan VK, Rao KV, Venkatesan P, Sankaran K. Reference values and prediction equations for maximal expiratory flow rates in non smoking subjects in Madras. Indian J Physiol Pharmacol 1993;37:2917.

11. Mohan Rao N. Pulmonary function tests in factories, field, laboratory and hospitals. Indian J Occup Health 1989;32:13-7.

12. Mead J, Turner JM, Macklem PT, Little JB. Significance of the relationship between lung recoil and maximum expiratory flow. J Appl Physiol 1967;22:95-108.

13. Pride NB, Permutts, Riley RI, Bromberger-Barnea B. Determinants of maximal expiratory flow volume and lungs. J Appl Physiol 1967;23:646-62.

14. Cowie RL. The influence of silicosis on deteriorating lung function in gold miners. Chest 1998;113:340-3.
15. Ng TP, Chan SL, Lam KP. Radiological progression and lung function in silicosis - A ten year follow up study. Br Med J (Clin Res Ed) 1987;295:164-8.

16. Kreiss K, Greenberg LM, Kogut SJ, Lezotte DC, Irvin CG, Cherniack RM. Hard-rock mining exposures affect smokers and nonsmokers differently. Results of a community prevalence study. Ann Rev Respir Dis 1989;139:1487-93.

17. Manfreda J, Sidwall G, Maini K, West P, Cherniack RM. Respiratory abnormalities in employees of the hard rock mining industry. Am Rev Respir Dis 1982;126:629-34.

Source of Support: Nil, Conflict of Interest: None declared.

\section{Author Help: Sending a revised article}

1) Include the referees' remarks and point to point clarification to those remarks at the beginning in the revised article file itself. In addition, mark the changes as underlined or coloured text in the article. Please include in a single file
a. referees' comments
b. point to point clarifications on the comments
c. revised article with text highlighting the changes done

2) Include the original comments of the reviewers/editor with point to point reply at the beginning of the article in the 'Article File'. To ensure that the reviewer can assess the revised paper in timely fashion, please reply to the comments of the referees/editors in the following manner.

- $\quad$ There is no data on follow-up of these patients.

Authors' Reply: The follow up of patients have been included in the results section [Page 3, para 2]

- $\quad$ Authors should highlight the relation of complication to duration of diabetes.

Authors' Reply: The complications as seen in our study group has been included in the results section [Page 4, Table] 